\title{
Comparative study of the efficiency of induction and gas cook-tops
}

See end of the paper for authors' affiliations

\section{J.K. GILL}

Department of Family Resource Management, College of Home Science, Punjab Agricultural University, LUDHIANA (PUNJAB) INDIA

Email : jkg1992@pau.edu
ABSTRACT : The comparison of efficiency of induction cook-top with gas cook-top was done by the selection of 120 respondents randomly from urban area under municipal corporation limits of Ludhiana city. An interview schedule was prepared to collect data from the respondents. The laboratory experiments were conducted to evaluate selected appliances on the basis of efficiency, time and money cost of induction cook-top and gas cook-top. On the basis of the results of household survey, two commonly prepared recipes were cooked on both the appliances. The organoleptic evaluation of the recipes namely: zeera rice and potato vegetable was done by a panel of judges. Induction cook-top was 60.18 per cent efficient than gas cook-top (19.07\%) due to hardly any loss of heat. Induction cook-top took more time to cook both the recipes as compared to gas cook-top, while cooking cost was less in induction cook-top in terms of money cost. Organoleptic scores of cooked recipies were statistically non-significant indicating that there were no differences in both the appliances in terms of cooked food. Therefore, it is suggested that the induction cook-top need to be popularized as it is cost effective and efficient than gas cook-top.

- KEY WORDS: Efficiency, Gas cook-top, Induction cook-top

- HOW TO CITE THIS PAPER : Kaur, M. and Gill, J.K. (2015). Comparative study of the efficiency of induction and gas cook-tops. Asian J. Home Sci., 10 (2) : 432-436. 